\title{
Modulation of Extracellular Levels of 5-HT in the Caudate Putamen of Freely Moving Rats by High Frequency Stimulation of the Subthalamic Nucleus
}

\author{
Kevin Joseph ${ }^{1,2, *}$, Ramya Varatharajan ${ }^{1,2}$, Sonya Carvalho Neto ${ }^{1}$, Ulrich G. Hofmann ${ }^{3,4}$, \\ Volker Tronnier ${ }^{5, \#}$ and Andreas Moser ${ }^{1, \#}$
}

${ }^{I}$ Neurochemical Research Group, Department of Neurology, University of Lübeck, Lübeck, Germany; ${ }^{2}$ Graduate School for Computing in Medicine and Life Science, Lübeck, Germany; ${ }^{3}$ Institute for Signal Processing, University of Lübeck, Lübeck, Germany; ${ }^{4}$ Department of Neurosurgery, University Medical Center, Freiburg, Germany; ${ }^{5}$ Department of Neurosurgery, University of Lübeck, Lübeck, Germany

\begin{abstract}
Electrical high frequency stimulation (HFS) in the subthalamic nucleus (STN) has been shown to have a therapeutic effect in several movement disorders. But, debilitating psychiatric effects like depression and suicidality are occasionally seen and might be caused by the changes in the serotoninergic activity. Previous studies could show that HFS of the STN results in inhibition of the serotonergic neurons originating in the dorsal raphe nucleus. The aim of this study was to characterize the effect of HFS $(124 \mathrm{~Hz}, 0.5 \mathrm{~mA})$ in the STN, on the extracellular levels of serotonin, dopamine and their metabolites HIAA, DOPAC and HVA in the caudate-putamen $(\mathrm{CPu})$ in conscious and freely moving rats. Extracellular levels of the neurotransmitters and their metabolites were quantified using high performance liquid chromatography with electrochemical detection. Under HFS conditions, a significant reduction in the extracellular levels of serotonin was observed. Cessation of HFS showed a recovery back to basal levels. Dopamine levels were not affected, although significant increase of its metabolites DOPAC and HVA were measured. In the case of low frequency stimulation (LFS), levels of serotonin and its metabolite HIAA remained unchanged, while the levels of dopamine metabolites, DOPAC and HVA, showed a significant decline. These results demonstrate evidence for a strong linkage between HFS in the STN and reduction of the levels of serotonin in the caudate-putamen, which is likely responsible for psychiatric side effects seen in Parkinsonian patients who are treated with STN stimulation.
\end{abstract}

Keywords: Caudate putamen, high frequency stimulation, rat, serotonin, subthalamic nucleus.

\section{INTRODUCTION}

Deep brain stimulation of the subthalamic nucleus (STN) has been used successfully as a treatment for alleviating the movement disabilities that are associated with Parkinson's disease $[1,2]$. In the case of advanced Parkinson's disease, electrical high frequency stimulation (HFS) at $130 \mathrm{~Hz}$, has been proved to provide cessation of resting tremor, rigidity and hypo- or bradykinesia, and also helps to reduce L-Dopa induced dyskinesia [3, 4]. Recent trials show that STN-HFS is superior to conventional medical management since it lead to a decrease in severity and duration of periods of immobility and dyskinesia. These changes led to an improvement in measurements of activities of daily living and bodily discomfort [5-7].

However, STN-HFS can also be unfortunately associated with debilitating non motor side effects, which include but are not limited to mood alterations and an increased mood alteration, psychosis, impulse control disorders and suicide risk $[3,8]$. Systematic reviews in clinical series showed that

*Address correspondence to this author at the Department of Neurology, University of Lübeck, Lübeck, Germany; Tel: +494515002930; Fax:+494515002489; E-mail: kevin.joseph@neuro.uni-luebeck.de

\# Shared Last Authorship up to $30 \%$ of patients developed depressive symptoms after the onset of STN- HFS $[9,10]$. Many of these effects that are seen to arise from high frequency stimulation of the STN (STN-HFS), are thought to arise from reduced functioning of the serotonergic (5-HT) neurons in the brain stem, which is the primary source for the 5-HT innervation to the forebrain. Evidence that STN-HFS affected the 5-HT mechanism has been provided recently, where bilateral stimulation of the STN was shown to inhibit the firing rate of 5HT neurons in the dorsal raphe nucleus (DRN) along with neurochemical studies that showed that the extracellular levels of 5HT in the prefrontal cortex and the hippocampus were significantly affected by STN-HFS [11]. The inhibition was noticeable during HFS and a prolonged inhibition of the 5-HT cell firing was observed $[12,13]$.

This study investigated the effect of unilateral HFS-STN on the extracellular concentration in the caudate putamen of freely moving rats, using in vivo microdialysis. Extracellular 5-HT release was quantified from the ipsilateral caudate putamen $(\mathrm{CPu})$, as it receives dense innervation from the DRN 5 -HT system $[14,15]$. The effects on the metabolic rate of the monoamines into their metabolites were also studied since changes in the metabolic rate could indicate larger neurochemical changes that need to be further studied and understood. 


\section{MATERIALS AND METHODS}

\subsection{Animals}

Male Wistar rats (300-350 grams; Janvier, France) were housed separately under standard lighting conditions $(12 \mathrm{~h}$ light-dark cycle, lights on 06:00 h - 18:00 h), $22^{\circ} \mathrm{C}$ and $40 \%$ humidity with free access to food and water. All procedures with animals were reviewed and approved by the University of Lübeck and the Ministry for Agriculture, the Environment and Rural Areas, Schleswig-Holstein, Germany, and were conducted in accordance with the NIH guide for the Care and Use of laboratory animals (NIH Guide for the Care and Use of Laboratory Animals, NIH Publication No. 85-23, 1985).

\subsection{Implant and Surgery}

The target region for electrical stimulation was the subthalamic nucleus (STN) and the microdialysis was carried out from the ipsilateral caudate-putamen $(\mathrm{CPu})$. A custom built double guiding cannula implant was crafted to target these regions. The double guide cannula consisted of a commercially available microdialysis cannula (CMA/11, Carnegie Medicine, Stockholm, Sweden) of which the tubing was replaced and shaped so as to accept the modified stimulation electrode, to which a commercially available microdialysis cannula (AT4.15.iC, AgnTho's, Lidingö, Sweden) was glued by two component epoxy resin under microscopic and micromanipulator control. The first cannula served as a guide for the concentric bipolar stimulation electrode with $250 \mu \mathrm{m}$ outer diameter (for details see section 2.4), whereas the second cannula served as a guide for the microdialysis probe

Prior to surgery, rats were pre-anesthetized with isoflurane and then, injected with $80 \mathrm{mg} / \mathrm{kg}$ ketamine (Ketavet ${ }^{\circledR}$, Pfizer) and $1 \mathrm{mg} / \mathrm{kg}$ xylazine (Rompun ${ }^{\circledR}$, Bayer) intraperitonially. The anesthetised rats were then placed into a stereotaxic frame where body temperature was maintained $\left(37^{\circ} \mathrm{C}\right)$. Once the skin was incised to expose the cranial landmarks, stereotactic coordinates derived from the Paxinos and Watson atlas (Paxinos and Watson, 2007) were used to locate the target regions. The coordinates used were $\mathrm{AP}_{\mathrm{B}}-3.8, \mathrm{ML}_{\mathrm{B}}-2.6$ and $\mathrm{DV}+7.8$ for the $\mathrm{STN}$, and $\mathrm{AP}_{\mathrm{B}}-1.0, \mathrm{ML}_{\mathrm{B}}-4.4$ and $\mathrm{DV}$ +6.0 for the $\mathrm{CPu}$. The implant was fixed in position using skull screws and dental cement. The animals were allowed to recover for 3 days after the surgery before the microdialysis experiments were carried out.

\subsection{Microdialysis}

After recovery time (Fig. 1), microdialysis experiments were carried out in conscious freely moving rats as described by Hiller et al. [16]. Experiments began with placing the rats in a bowl (Plexiglas, $50 \mathrm{~cm}$ diameter). Subsequently, the microdialysis probe with a $4 \mathrm{~mm}$ membrane (Agn Tho's, AT4 series, 6 KDa cutoff) and $240 \mu \mathrm{m}$ diameter was inserted into the corresponding implanted guiding cannula to a depth of DV+6.0 mm from the dural surface. Additionally, a modified bipolar concentric stimulation electrode, with a $45^{\circ}$ beveled tip with an internal diameter of $250 \mu \mathrm{m}$ was inserted to a depth of DV+7.8 from the dural surface (Paxinos and Watson, 2007).

For all experiments, the microdialysis probe was continuously perfused with artificial cerebrospinal fluid (aCSF) with a flow rate of $1.2 \mu \mathrm{l} / \mathrm{min}$. The aCSF was composed of $125 \mathrm{mM} \mathrm{NaCl}, 25 \mathrm{mM} \mathrm{NaHCO}{ }_{3}, 1 \mathrm{mM} \mathrm{MgSO}{ }_{4} * 7 \mathrm{H}_{2} \mathrm{O}, 2$ $\mathrm{mM} \mathrm{CaCl} 2 * 2 \mathrm{H}_{2} \mathrm{O}, 5 \mathrm{mM} \mathrm{KCl}, 1.25 \mathrm{mM} \mathrm{KH}_{2} \mathrm{PO}_{4}$ (Merck Chemicals) and $0.1 \mathrm{mM}$ ascorbic acid (Sigma-Aldrich), dissolved in HPLC grade $\mathrm{H}_{2} \mathrm{O}$ (J.T. Baker), and the $\mathrm{pH}$ was adjusted to $7.4[17,18]$.

The microdialysis probe was perfused with aCSF for 120 minutes before sample collection began. Samples were collected every 20 minutes for 12 consecutive fractions. $24 \mu 1$ of dialysate was collected into $5 \mu 13.3 \%$ perchloric acid (Merck Chemicals). Once the neurotransmitter values stabilized, 3 x 20 min samples were collected to obtain a baseline value followed by $2 \times 20$ min during stimulation and $6 \times 20$ min post stimulation (Fig. 1). All collected samples were stored at $-30{ }^{\circ} \mathrm{C}$, and subsequently measured by means of high performance liquid chromatography (HPLC) with electrochemical detection (ED).

\subsection{STN Stimulation Protocol}

Bipolar platinum-iridium (Pt/Ir) electrodes (GBCBG30, FHC Inc., Maine) were used, with the cathode in the center (diameter $75 \mu \mathrm{m}$ ), concentrically surrounded by an anode [19]. The total area of the smaller inner contact was $0.0062 \mathrm{~mm}^{2}$. For the stimulation, the electrodes were connected to a stimulator (Isostim A320D, WPI, Germany). The stimulation parameters used varied for the STN-HFS (High Frequency Stimulation) group and the STN-LFS (Low Frequency Stimulation) group.

The animals were grouped based on the stimulation parameters, HFS $(n=9)$, LFS $(n=16)$ and non-stimulated control $(n=15)$. For STN-HFS, animals were stimulated with mono-

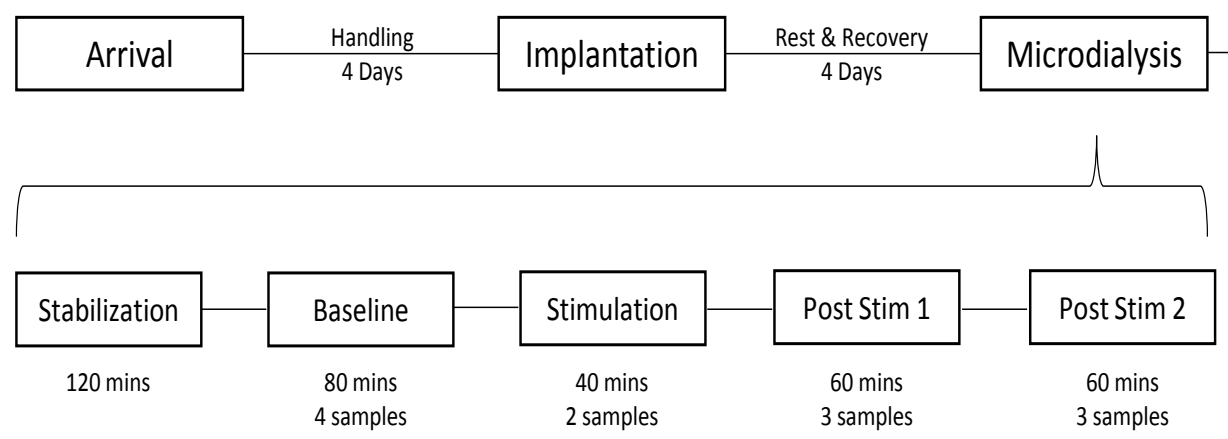

Fig. (1). Experimental layout. Shows grouping of samples and whole schematic for the experiments carried out. 
phasic, rectangular pulses at $124 \mathrm{~Hz}, 0.5 \mathrm{~mA}$ constant current, $8 \mathrm{~ms}$ pulse width and $60 \mu \mathrm{s}$ pulse duration. The parameters were chosen on the basis of previous experiments (Hiller et al., 2007). For STN-LFS, animals were stimulated with monophasic, rectangular pulses with frequency of $30 \mathrm{~Hz}$ and $0.5 \mathrm{~mA}$ constant current. Pulse width was controlled on-line by an oscilloscope (Tektronic 2004B) in parallel with the electrode. In non-stimulated control animals, the electrode was inserted into the guide cannula and connected to the stimulator without stimulation.

\subsection{HPLC-ED}

The dialysates were analyzed for serotonin (5-HT), 5hydroxyindoleacetic acid (HIAA), dopamine (DA), 3, 4dihydroxyphenylacetic acid (DOPAC) and homovanillic acid (HVA) using HPLC-ED. The HPLC system consisted of a C18 column (Eurospher RP $18.5 \mu \mathrm{m}$, column size $250 \times 4$ $\mathrm{mm}$ with a pre-column $35 \times 4 \mathrm{~mm}$ ). The isocratic mobile phase $(0.15 \mathrm{M}$ sodium acetate buffer, $\mathrm{pH} 4.0$, containing $0.05 \mathrm{mM}$ EDTA, $0.1 \mathrm{mM}$ sodium octyl sulphate, and $12 \%$ methanol) [20], previously degassed with helium, had a flow rate of $1.0 \mathrm{ml} / \mathrm{min}$ (Smartline pump 1050, Knauer, Berlin, Germany) in a temperature-controlled environment $\left(30{ }^{\circ} \mathrm{C}\right)$. The dialysates were detected electrochemically using a glassy carbon electrode set at a potential of $800 \mathrm{mV}$ relative to an $\mathrm{Ag} / \mathrm{AgCl}$ reference electrode (Electrochemical Detector CLC 100, Chromsystems GmbH, Munich, Germany). Calibration was carried out daily using standard solutions of the substances we measured.

\subsection{Statistical Analysis}

Microdialysis data is presented as percentages of the mean of four baseline samples prior to STN stimulation. The effect of HFS on extracellular neurotransmitters and their metabolites was assessed statistically by comparing the normalized values over 4 time periods (baseline, stimulation, post-stimulation 1 and post-stimulation 2) using student's ttests for pairwise comparisons. Mean neurotransmitter and metabolite values were expressed in $\mathrm{nM} \pm$ standard error (SEM). Differences between the groups were assessed with one-way analysis of variance (ANOVA) with post hoc analysis for pairwise comparisons, as mentioned.

\section{RESULTS}

The basal concentrations in all three groups (Control, STN-HFS and STN-LFS) of dopamine (DA) and serotonin (5-HT) and their metabolites, 3,4-dihydroxyphenylacetic acid (DOPAC) and homovanillic acid (HVA) and 5- hydroxyindoleacetic acid (HIAA) respectively, could be quantified in the nanomolar concentration in the dialysates from the caudate putamen of the rat (Table 1). The basal levels of the neurotransmitters showed no significant changes between the three groups of animals. To reduce the effect of interindividual differences of the basal value concentration of the neurotransmitters and their metabolites, the values were normalized and the basal values were set to be $100 \%$.

It was observed that the metabolic rate of 5-HT to HIAA was higher than the metabolic rate of dopamine to its metabolite, HVA, by the ratio of 5-HT: HIAA vs. DA: HVA during the basal time period (Table 2). When STN-HFS was carried out, the metabolic rate of 5-HT to HIAA showed a tendency to decrease. In the case of dopamine, the metabolic rate was decreased resulting in an increase in the metabolite concentrations during the stimulation time period. When LFS was carried out, the metabolic rate of 5-HT to HIAA remained constant and no change was observed. However a marked reduction in the dopamine metabolism to its metabolites, DOPAC and HVA was observed (Table 3).

Table 1. Basal concentrations of neurotransmitters and their metabolites from the rat caudate putamen $(\mathrm{CPu})$. Concentration expressed in $\mathbf{n M} \pm \mathrm{SEM}$.

\begin{tabular}{|c|c|c|c|}
\hline \multicolumn{4}{|c|}{ Basal Levels } \\
\hline Dialysate & Control & High Freq. Stim. & Low Freq. Stim. \\
\hline \hline $5-H T$ & $3.03 \pm 0.46$ & $2.94 \pm 0.26$ & $3.29 \pm 0.27$ \\
\hline$H I A A$ & $24.44 \pm 5.93$ & $21.17 \pm 3.35$ & $22.32 \pm 3.22$ \\
\hline$D A$ & $15.94 \pm 5.01$ & $19.23 \pm 2.56$ & $15.68 \pm 0.70$ \\
\hline$D O P A C$ & $37.94 \pm 4.97$ & $32.81 \pm 5.07$ & $32.51 \pm 3.83$ \\
\hline$H V A$ & $50.55 \pm 4.91$ & $50.61 \pm 8.84$ & $55.82 \pm 4.95$ \\
\hline
\end{tabular}

Table 2. The ratio of basal levels of neurotransmitters as measured from the rat caudate putamen. Expressed in Ratio \pm SEM.

\begin{tabular}{|c|c|c|c|}
\hline & \multicolumn{3}{|c|}{ Ratio of Neurotransmitter to Metabolite } \\
\hline & Control & High Freq. Stim. & Low Freq. Stim. \\
\hline \hline 5-HT: HIAA & $0.14 \pm 0.02$ & $0.16 \pm 0.02$ & $0.16 \pm 0.02$ \\
\hline DA: $H V A$ & $0.35 \pm 0.15$ & $0.37 \pm 0.07$ & $0.30 \pm 0.04$ \\
\hline DA: $D O P A C$ & $0.37 \pm 0.12$ & $0.43 \pm 0.06$ & $0.31 \pm 0.06$ \\
\hline
\end{tabular}

Table 3. The ratio of concentration of neurotransmitters during stimulation as measured from the rat caudate putamen during (A) and after stimulation (B).

(A)

\begin{tabular}{|c|c|c|}
\hline \multicolumn{3}{|c|}{ Ratio } \\
\hline & H.F.S & L.F.S \\
\hline \hline 5-HT: HIAA & $0.25 \pm 0.04$ & $0.21 \pm 0.02$ \\
\hline DA: $H V A$ & $0.39 \pm 0.07$ & $0.53 \pm 0.12$ \\
\hline DA: DOPAC & $0.34 \pm 0.07$ & $0.48 \pm 0.09$ \\
\hline
\end{tabular}

(B)

\begin{tabular}{|c|c|c|}
\hline \multicolumn{3}{|c|}{ Ratio } \\
\hline & H.F.S & L.F.S \\
\hline \hline 5-HT: HIAA & $0.30 \pm 0.08$ & $0.21 \pm 0.02$ \\
\hline DA: $H V A$ & $0.39 \pm 0.06$ & $0.79 \pm 0.16^{*}$ \\
\hline$D A: D O P A C$ & $0.32 \pm 0.05$ & $0.67 \pm 0.11$ \\
\hline
\end{tabular}


In comparison to non-stimulated sham operated controls, high frequency stimulation of the subthalamic nucleus (STN) for 40 minutes resulted in a delayed but statistically significant decrease in the levels of 5-HT in the ipsilateral caudate putamen (Fig. 2). This effect persisted and was present for 40 minutes after stimulation was ceased. 140 minutes later during the experiment, the extracellular levels of 5-HT reached near baseline levels again. STN-HFS caused significant decrease in the extracellular levels of HIAA (Table 4). STN-LFS had no significant effects on extracellular levels of either 5-HT or 5-HIAA.

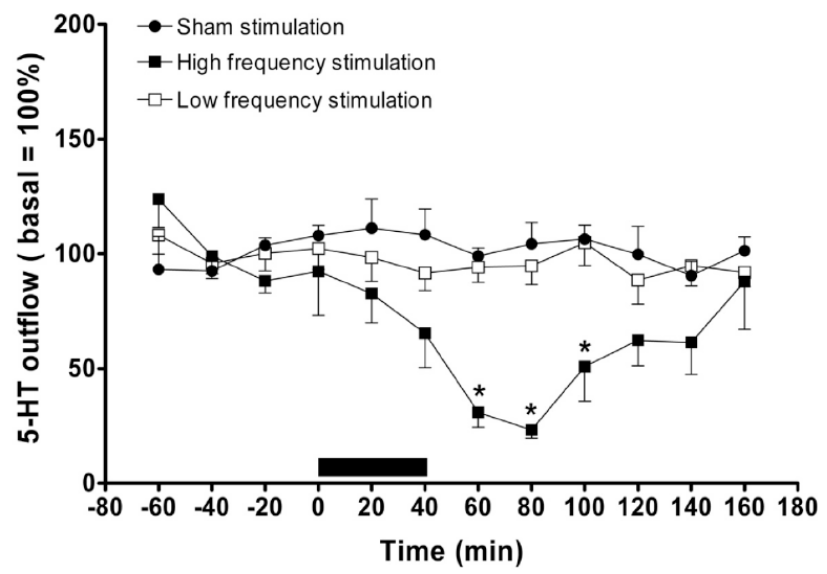

Fig. (2). 5-HT outflow was measured in the dialysate from the caudate putamen of freely moving rats by HPLC with electrochemical detection. Data are mean \pm SEM expressed in percent of basal values $(=100 \%)$. 5 -HT outflow in animals treated with HFS $(n=9)$ decreased after stimulation where as in control group $(n=15)$ without HFS and animal treated with LFS $(n=16)$ there was no significant change in 5-HT outflow compared to baseline values.

Neither STN-HFS nor STN-LFS altered the extracellular levels of dopamine (Table 5). When compared to nonstimulated sham controls, STN-HFS led to a stable and significant increase in the levels of the metabolites of dopamine, DOPAC and HVA, in the caudate putamen. In contrast to the STN-HFS results, STN-LFS caused a significant decrease in the extracellular levels of DOPAC and HVA in the ipsilateral caudate putamen (Table 5).

No behavioral change was observed before, during or after STN-HFS (data not shown).

\section{DISCUSSION}

Clinically, deep brain stimulation (DBS), particularly DBS of the subthalamic nucleus (STN) has been linked to psychiatric symptoms as side effects that are associated with serotonergic dysfunction, such as impulsivity, depression and increase of suicidal thoughts and behavior [21,22]. One of the most important mortality risks following DBS by high frequency stimulation of the STN (STN-HFS) in advanced Parkinson's disease is suicide [8]. In this respect, Temel et $a l$. found in animal experiments that STN-HFS inhibited the firing rate of serotonergic neurons in the dorsal raphe nucleus (DRN) and aggravated depressive behavior in rats that were subjected to the forced swim test [12]. Additionally, a review by Miguelez et al. gave insights into the modification of different serotonin receptor subclasses in Parkinson's dis- ease and assumed that in the basal ganglia nuclei, serotonergic innervations come mainly from the DRN [23].

Thus, in this in-vivo neurochemical study the question was raised whether electrical stimulation of the STN modulates the extracellular serotonin levels in the caudateputamen $(\mathrm{CPu})$ of the rat, and whether these interactions were visible when different stimulation parameters, i.e., high (STN-HFS) or low (STN-LFS) frequencies were applied to the STN. The results described above indicate that when simultaneous microdialysis from the ipsilateral $\mathrm{CPu}$ was carried out during STN-HFS, extracellular serotonin (5-HT) levels significantly decreased implying the modification of 5-HT neuronal activity.

As proposed by Feuerstein et al. [24], GABAergic axons originating in the globus pallidus externus (GPe), are activated by DBS of the STN to release GABA into the STN. The theory that HFS is affecting the GABAergic fibers projecting to the STN with an increase of the inhibitory GABAergic activity was supported by the observation that the most effective HFS site is located dorsal/dorsomedial to the STN, in the region of the pallidofugal fibers $[25,26]$. Therefore, it was assumed that STN-HFS moderates the glutamatergic drive to the globus pallidus internus (GPi) and the substantia nigra pars reticulata (SNr) [24]. Rosenbaum et al. showed that placement of the electrode and the amplitude of stimulation maximized the number of STN axons activated and will suppress the transfer of $\beta$-oscillations and synchrony from the STN to GPi [27]. These authors described the following connections between STN and serotonergic neurons of the dorsal raphe nucleus in relation to 5-HT-associated side effects of STN-HFS: The STN receives GABAergic projections from the GPe and has glutamatergic projections to the GPi. GABAergic neurons from the GPi project to the thalamus and the lateral habenula (LH) [24]. The LH plays the most important role since it has glutamatergic afferents to the dorsal raphe nuclei (DRN), which via GABAergic interneurons regulate the serotonergic network projecting to the $\mathrm{CPu}$, the prefrontal cortex, and the hippocampus [8$10,12]$. Our finding with a significant decrease of 5-HT in the $\mathrm{CPu}$ when the STN was stimulated electrically by high frequencies $(124 \mathrm{~Hz})$ is, therefore, absolutely in line with the assumptions of Feuerstein et al. [24] and also corroborates the electrophysiological results of Temel et al. and Tan et al. that serotonergic DRN neurons to the $\mathrm{CPu}$ are inhibited by STN-HFS [12, 28]. Additionally, findings from Reymann et al. give also evidence that the STN plays a role in social behavior and anxogenic like behavior in rodents; thus, these authors proposed that DBS could result in an abnormal brain state where anxiety and social behavior is affected [29]. In this context, Kiser et al. conclude that serotonin is positively correlated with sensitivity to social factors and modulates social behavior depending on the nature of social factors [30].

We could, additionally, demonstrate that modification of extracellular 5-HT levels continued well after the stimulation was ceased, but also that the changes were not permanent but reversible over time. We do not have a sufficient explanation for this phenomenon; that STN-HFS leads to an attenuating network oscillation over time is possible but rather speculative. Electrophysiological studies indeed indicated that STNHFS suppresses oscillatory $\beta$-activities or synchronization in 
Table 4. Mean value \pm SEM of 5-HT and HIAA from rat caudate nucleus. Values are given for control animals (sham stimulated) $(n=15)$, LFS-STN $(n=16)$, and HFS-STN $(n=9)$. All values are expressed in percentage and are expressed with respect to baseline $=\mathbf{1 0 0 \%}$. Basal is baseline period, Stim is Stimulation period, Post Stim 1 is Post Stimulation period 1 and Post Stim 2 is Post Stimulation period 2. \# represents $\mathbf{p}<0.0001$ and * represents $\mathbf{p}<0.01$ compared with basal values.

\begin{tabular}{|c|c|c|c|c|c|c|}
\hline & \multicolumn{3}{|c|}{ 5-HT } & & HIAA \\
\cline { 2 - 7 } & HFS & LFS & Control & HFS & LFS & $100 \pm 5.5$ \\
\hline \hline Basal & $100 \pm 5.7$ & $100 \pm 4.7$ & $100 \pm 7.6$ & $100 \pm 9.1$ & $700 \pm 8.9$ \\
\hline Stim & $80 \pm 11$ & $96 \pm 6.7$ & $103 \pm 9.5$ & $92 \pm 9.2$ & $91 \pm 7.3$ \\
\hline Post Stim 1 & $38 \pm 6.5 \#$ & $106 \pm 6.5$ & $96 \pm 6.2$ & $74 \pm 12 *$ & $101 \pm 12$ & $90 \pm 8.9$ \\
\hline Post Stim 2 & $76 \pm 11 *$ & $96 \pm 7.7$ & $97 \pm 8$ & $69 \pm 11 *$ & $96 \pm 16$ & $96 \pm 23$ \\
\hline
\end{tabular}

Table 5. Mean value \pm SEM of DA, DOPAC and HVA from rat caudate nucleus. Values are given for control animals (sham stimulated) $(n=15)$, LFS-STN $(n=16)$, and HFS-STN $(n=9)$. All values are expressed in percentage and are expressed with respect to baseline $=100 \%$. Basal is baseline period, Stim is Stimulation period, Post Stim 1 is Post Stimulation period 1 and Post Stim 2 is Post Stimulation period 2. \# represents $p<0.001$ and * represents $p<0.01$ compared with basal values.

\begin{tabular}{|c|c|c|c|c|c|c|c|c|c|}
\hline & \multicolumn{3}{|c|}{ Dopamine } & \multicolumn{3}{c|}{ Dopac } & \multicolumn{3}{c|}{ HVA } \\
\cline { 2 - 10 } & HFS & LFS & Control & HFS & LFS & Control & HFS & LFS & Control \\
\hline \hline Basal & $100 \pm 9.6$ & $100 \pm 4.7$ & $100 \pm 15$ & $100 \pm 8.9$ & $100 \pm 4.6$ & $100 \pm 3.9$ & $100 \pm 8.2$ & $100 \pm 4.5$ & $100 \pm 4.8$ \\
\hline Stim & $115 \pm 21$ & $99 \pm 7.5$ & $97 \pm 21$ & $155 \pm 30$ & $88 \pm 6.1$ & $94 \pm 7.5$ & $167 \pm 26 *$ & $87 \pm 8.3$ & $114.1 \pm 12$ \\
\hline Post Stim 1 & $105 \pm 22$ & $106 \pm 5.3$ & $103 \pm 16$ & $126 \pm 22$ & $87 \pm 5.3 \#$ & $102 \pm 8.2$ & $108 \pm 20$ & $79 \pm 3.8 \#$ & $103 \pm 7.3$ \\
\hline Post Stim & $107 \pm 20$ & $108 \pm 6.3$ & $102 \pm 13$ & $136 \pm 22$ & $98 \pm 15$ & $98 \pm 9$ & $121 \pm 18$ & $77 \pm 3.6 \#$ & $94 \pm 6.2$ \\
\hline
\end{tabular}

parkinsonian patients [31, 32]. It is, however, unclear whether these electrophysiological findings are related to biochemical changes. The prolonged inhibition effect of STN-HFS could probably be attributed to changes in synaptic plasticity at the level of the STN [22]. Therefore, instead of being a simple and direct mechanism, STN-HFS may be responsible for altered function of the neural network between the STN and the DRN.

The effect of lowered 5-HT levels was only limited to high frequency stimulation. When the STN was subjected to low frequency stimulation $(30 \mathrm{~Hz})$, we did not see an effect on the levels of 5-HT or HIAA. Hence we can infer that the change in the 5-HT neuronal activity is frequency specific. HIAA levels showed a trend to decrease when STNHFS was carried out. The decline that was measured in the HIAA levels could be explained to be linked to the decrease in the 5-HT neuronal activity.

When STN-HFS was carried out, significant changes could not be observed in the extracellular levels of dopamine (DA). However, significant increase in its metabolites, 3, 4dihydroxyphenylacetic acid (DOPAC) and homovanillic acid (HVA) was measured compared to baseline values. These isolated effects on both dopamine metabolites without modification of extracellular dopamine itself after STN stimulation were expected and confirm earlier studies on native and also 6-hydroxydopamine-lesioned rats from Meisner et al. $[33,34]$. They argued that extracellular dopamine levels do not necessarily reflect concentrations at the synaptic cleft [17]. This assumption was corroborated by findings of Sabol et al. [35] and Diana et al. [36] who could demonstrate only an isolated increase of extracellular striatal DOPAC in rats turning on a treadmill although dopaminergic neurons exhibited increased firing. Thus, enhancement of DOPAC and HVA could give an indirect advice of an activation of the dopaminergic system by electrical STN stimulation. In this context it was suggested by Zetterström et al. [37] and also Imperio \& Di Chiara [38] that extracellular DOPAC and HVA levels may indicate intraneuronal dopamine synthesis. Since electrical high frequency stimulation indeed led to an increase in firing activity of nigral DA neurons [39], it should be stated that extracellular dopamine levels measured from micro dialysate samples from the $\mathrm{CPu}$ do definitively not reflect dopaminergic activity of the nigrostriatal pathway. According to Feuerstein et al. [24], STN-HFS reinforce GABAergic inhibition on glutamatergic neurons of the STN. This leads to a decline of glutamatergic activity on substantia nigra pars reticulata $(\mathrm{SNr})$. Since dopaminergic neurons in the substantia nigra pars compacta $(\mathrm{SNc})$ are inhibited by GABAergic afferents from the $\mathrm{SNr}$ [40] and STN-HFS is presumed to indirectly inhibit these GABAergic neurons [39], high frequency stimulation induce SNc disinhibition with an increase of dopaminergic activity and metabolism.

When low frequency stimulation (STN-LFS) was carried out, there was no effect on dopamine levels as found in STNHFS, but a significant drop in extracellular levels of both DOPAC and HVA. The decrease did not recover over the time period of the experiments that were conducted up to 120 minutes. This finding led us to suggest that the basal ganglia network is also susceptible to STN-LFS [41-43], 
although another biochemical mechanism should be discussed as in the case of STN-HFS. It has been reported that STN-LFS $(<30 \mathrm{~Hz})$ in humans can impair movement with slow distal upper limb movements and worsening of akinesia in Parkinson's patients [26,41], which could be explained by an activation of the glutamatergic efferents from the STN.

Taken together, our results provide evidence that electrical high frequency stimulation of the subthalamic nucleus causes indeed a significant decrease in the 5-HT neuronal activity in the caudate-putamen of the rat probably as a result of inhibition of serotonergic neurons arising from the DRN. This effect was found to be frequency dependent and was only seen with high frequency stimulation $(124 \mathrm{~Hz})$. The dopaminergic system was also affected by STN stimulation with modulation of extracellular DOPAC and HVA levels but without biochemical changes of extracellular dopamine.

\section{LIST OF ABBREVIATIONS}

\begin{tabular}{|c|c|c|}
\hline HFS & $=$ & High Frequency Stimulation \\
\hline LFS & $=$ & Low Frequency Stimulation \\
\hline STN & $=$ & Subthalamic nucleus \\
\hline $5 \mathrm{HT}$ & $=$ & 5-Hydroxytryptamine \\
\hline HIAA & $=$ & 5-Hydroxyindolic acid \\
\hline DA & $=$ & Dopamine \\
\hline DOPAC & $=$ & 3, 4-Dihydroxyphenylacetic acid \\
\hline HVA & $=$ & Homovanillic acid \\
\hline $\mathrm{CPu}$ & $=$ & Caudate putamen \\
\hline LFS & $=$ & Low frequency Stimulation \\
\hline L-Dopa & $=$ & Levo-Dopa \\
\hline DRN & $=$ & Dorsal raphe nucleus \\
\hline $\mathrm{aCSF}$ & $=$ & Artificial cerebrospinal fluid \\
\hline HPLC-ED & $=$ & $\begin{array}{l}\text { High Pressure Liquid Chromatography with } \\
\text { Electrochemical Detection }\end{array}$ \\
\hline DBS & $=$ & Deep Brain Stimulation \\
\hline GABA & $=$ & Gamma-aminobutyric acid \\
\hline GPe & $=$ & Globus pallidus externus \\
\hline GPi & $=$ & Globus Pallidus Internus \\
\hline $\mathrm{SNr}$ & $=$ & Substantia nigra pars reticulata \\
\hline $\mathrm{LH}$ & $=$ & Lateral habenula \\
\hline $\mathrm{SNc}$ & $=$ & Substantia nigra pars compacta \\
\hline
\end{tabular}

\section{CONFLICT OF INTEREST}

The authors confirm that this article content has no conflicts of interest.

\section{ACKNOWLEDGEMENTS}

K. Joseph and R. Varatharajan acknowledge the support by the Graduate School for computing in medicine and life sciences, funded by Germany's Excellence Initiative [DFG GSC 235/1].

\section{PATIENT'S CONSENT}

Declared none.

\section{REFERENCES}

[1] Gross RE, Lozano AM. Advances in neurostimulation for movement disorders. Neurol Res 2000; 22(3): 247-58.

[2] Tronnier VM, Fogel W, Krause M, et al. High frequency stimulation of the basal ganglia for the treatment of movement disorders: current status and clinical results. Minim Invasive Neurosur 2002; 45(2): 91-6.

[3] Berney A, Vingerhoets F, Perrin A, et al. Effect on mood of subthalamic DBS for Parkinson's disease: A consecutive series of 24 patients. Neurology 2002; 59(9): 1427-9.

[4] Benabid AL, Chabardes S, Mitrofanis J, Pollak P. Deep brain stimulation of the subthalamic nucleus for the treatment of Parkinson's disease. Lancet Neurol 2009; 8(1): 67-81.

[5] Deuschl G, Schade-Brittinger C, Krack P, et al. A randomized trial of deep-brain stimulation for Parkinson's disease. N Engl J Med 2006; 355(9): 896-908.

[6] Weaver FM, Stern M, Harris C, et al. Bilateral deep brain stimulation vs best medical therapy for patients. JAMA 2009; 301: 63-73.

[7] Williams A, Gill S, Varma T, et al. Deep brain stimulation plus best medical therapy versus best medical therapy alone for advanced Parkinson's disease (PD SURG trial): a randomised, open-label trial. Lancet Neurol 2010; 9(6): 581-91.

[8] Voon V, Krack P, Lang AE, et al. A multicentre study on suicide outcomes following subthalamic stimulation for Parkinson's disease. Brain 2008; 131(10): 2720-8.

[9] Temel Y, Kessels A, Tan S, Topdag A, Boon P, Visser-Vandewalle V. Behavioural changes after bilateral subthalamic stimulation in advanced Parkinson disease: a systematic review. Parkinsonism Relat Disord 2006; 12(5): 265-72.

[10] Appleby BS, Duggan PS, Regenberg A, Rabins P V. Psychiatric and neuropsychiatric adverse events associated with deep brain stimulation: A meta-analysis of ten years' experience. Mov Disord 2007; 22(12): 1722-8.

[11] Navailles S, Benazzouz A, Bioulac B, Gross C, De Deurwaerdere P. High-frequency stimulation of the subthalamic nucleus and L3,4-dihydroxyphenylalanine inhibit in vivo serotonin release in the prefrontal cortex and hippocampus in a rat model of Parkinson's disease. J Neurosci 2010; 30(6): 2356-64.

[12] Temel Y, Boothman LJ, Blokland A, et al. Inhibition of 5-HT neuron activity and induction of depressive-like behavior by highfrequency stimulation of the subthalamic nucleus. Proc Natl Acad Sci USA 2007; 104(43): 17087-92.

[13] Hartung H, Tan SKH, Steinbusch HMW, Temel Y, Sharp T. Highfrequency stimulation of the subthalamic nucleus inhibits the firing of juxtacellular labelled 5-HT-containing neurones. J Neuroscience 2011; 186: 135-45.

[14] O'Hearn E, Molliver M. Organization of raphe-cortical projections in rat: a quantitative retrograde study. Brain Res Bull 1984; 13(6): 709-26.

[15] Wallman M-J, Gagnon D, Parent M. Serotonin innervation of human basal ganglia. Eur J Neurosci 2011; 33(8): 1519-32.

[16] Hiller A, Loeffler S, Haupt C, Litza M. Electrical high frequency stimulation of the caudate nucleus induces local GABA outflow in freely moving rats. J Neurosci Methods 2007; 159(2): 286-90.

[17] Butcher SP, Fairbrother IS, Kelly JS, Arbuthnott GW. Amphetamine-induced dopamine release in the rat striatum: an in vivo microdialysis study. J Neurochem 1988; 50(2): 346-55.

[18] Thümen A, Behnecke A, Qadri F, Bäuml E, Behnecke CA, Moser A. N-methyl-norsalsolinol, a putative dopaminergic neurotoxin, passes through the blood-brain barrier in vivo. Neuroreport 2002; 13(1): 25-8.

[19] Harnack D, Winter C, Meissner W, Reum T, Kupsch A, Morgenstern R. The effects of electrode material, charge density and stimulation duration on the safety of high-frequency stimulation of the subthalamic nucleus in rats. J Neurosci Methods 2004; 138(1-2): 207-16.

[20] Thümen A, Behnecke A, Qadri F, Moser A. N-methyl-norsalsolinol modulates serotonin metabolism in the rat caudate nucleus: 
correlation with behavioural changes. Int J Neuropsychopharmacol 2003; 6(1): 35-40

[21] Temel Y, Blokland A, Steinbusch HWM, Visser-Vandewalle V. The functional role of the subthalamic nucleus in cognitive and limbic circuits. Prog Neurobiol 2005; 76: 393-413.

[22] Tan SKH, Hartung H, Visser-Vandewalle V, Steinbusch HWM, Temel Y, Sharp T. A combined in vivo neurochemical and electrophysiological analysis of the effect of high-frequency stimulation of the subthalamic nucleus on 5-HT transmission. Exp Neurol 2012; 233(1): 145-53

[23] Miguelez C, Morera-Herreras T, Torrecilla M, Ruiz-Ortega JA, Ugedo L. Interaction between the 5-HT system and the basal ganglia: functional implication and therapeutic perspective in Parkinson's disease. Front Neural Circuits 2014; 8: 21.

[24] Feuerstein TJT, Kammerer M, Lücking CH, Moser A. Selective GABA release as a mechanistic basis of high-frequency stimulation used for the treatment of neuropsychiatric diseases. Naunyn Schmiedebergs Arch Pharmacol 2011; 384(1):1-20.

[25] Plaha P, Ben-Shlomo Y, Patel NK, Gill SS. Stimulation of the caudal zona incerta is superior to stimulation of the subthalamic nucleus in improving contralateral parkinsonism. Brain 2006; 129(pt 7): 1732-47.

[26] Hammond C, Ammari R, Bioulac B, Garcia L. Latest view on the mechanism of action of deep brain stimulation. Mov Disord 2008; 23(15): 2111-21

[27] Rosenbaum R, Zimnik A, Zheng F, et al. Axonal and synaptic failure suppress the transfer of firing rate oscillations, synchrony and information during high frequency deep brain stimulation. Neurobiol Dis 2014; 62: 86-99.

[28] Tan SKH, Janssen MLF, Jahanshahi A, et al. High frequency stimulation of the subthalamic nucleus increases c-fos immunoreactivity in the dorsal raphe nucleus and afferent brain regions. J Psychiatr Res 2011; 45(10): 1307-15.

[29] Reymann JM, Naudet F, Pihan M, Saïkali S, Laviolle B, BentuéFerrer D. Subthalamic nucleus modulates social and anxogenic-like behaviors. Behav Brain Res 2013; 252: 356-62.

[30] Kiser D, Steemers B, Branchi I, Homberg JR. The reciprocal interaction between serotonin and social behaviour. Neurosci Biobehav Rev 2012; 36(2): 786-98.

[31] Eusebio A, Thevathasan W, Gaynor DL, et al. Deep brain stimulation can suppress pathological synchronisation in parkinsonian patients. J Neurol Neurosurg Psychiatry 2011; 82(5): 569-73.

[32] Kühn A, Kempf F, Brücke C, et al. High-frequency stimulation of the subthalamic nucleus suppresses oscillatory beta activity in patients with Parkinson's disease in parallel with improvement in motor performance. J Neurosci 2008; 28(24): 6165-73.

[33] Meissner W, Reum T, Paul G, et al. Striatal dopaminergic metabolism is increased by deep brain stimulation of the subthalamic nucleus in 6-hydroxydopamine lesioned rats. Neurosci Lett 2001; 303(3): 165-8.

[34] Meissner W, Harnack D, Paul G, et al. Deep brain stimulation of subthalamic neurons increases striatal dopamine metabolism and induces contralateral circling in freely moving 6hydroxydopamine-lesioned rats. Neurosci Lett 2002; 328: 105-8.

[35] Sabol KE, Richards JB, Freed CR. In vivo dialysis measurements of dopamine and DOPAC in rats trained to turn on a circular treadmill. Pharmacol Biochem Behav 1990; 36(1): 21-8.

[36] Diana M, Garcia-Munoz M. Electrophysiological analysis of dopamine cells from the substantia nigra pars compacta of circling rats. Exp Brain Res 1989; 74(3): 625-30.

[37] Zetterström T, Sharp T, Ungerstedt U. Further evaluation of the mechanism by which amphetamine reduces striatal dopamine metabolism : a brain dialysis study. Eur J Pharmacol 1986; 132(1): $1-9$.

[38] Imperato A, Di Chiara G. Effects of locally applied D-1 and D-2 receptor agonists and antagonists studied with brain dialysis. Eur J Pharmacol 1988; 156(3): 385-93.

[39] Benazzouz A, Gao D, Ni Z, Benabid A-L. High frequency stimulation of the STN influences the activity of dopamine neurons in the rat. Neuroreport 2000; 11(7): 1593-6.

[40] Grace AA, Bunney BS. Paradoxical GABA excitation of nigral dopaminergic cells: indirect mediation through reticulata inhibitory neurons. Eur J Pharmacol 1979; 59(3-4): 211-8.

[41] Eusebio A, Chen CC, Lu CS, et al. Effects of low-frequency stimulation of the subthalamic nucleus on movement in Parkinson's disease. Exp Neurol 2008; 209(1): 125-30.

[42] Moro E, Esselink RJA, Xie J, Hommel M, Benabid AL, Pollak P. The impact on Parkinson's disease of electrical parameter settings in STN stimulation. Neurology 2002; 59(5): 706-13.

[43] Timmermann L, Wojtecki L, Gross J, et al. Ten-Hertz stimulation of subthalamic nucleus deteriorates motor symptoms in Parkinson's disease. Mov Disord 2004; 19(11): 1328-33.

Received: October 27, 2014
(C) Joseph et al.; Licensee Bentham Open.

Revised: December 11, 2014

Accepted: December 16, 2014

This is an open access article licensed under the terms of the Creative Commons Attribution Non-Commercial License (http://creativecommons.org/licenses/by-nc/3.0/) which permits unrestricted, non-commercial use, distribution and reproduction in any medium, provided the work is properly cited. 